\title{
TECNOLOGIA DA INFORMAÇÃO: IMPACTOS NA SOCIEDADE
}

\author{
Gercina Ângela Borém de O. Lima \\ Líliam Pacheco Pinto \\ Marconi Martins de Laia
}

\begin{abstract}
Resumo
Estuda os conceitos dos termos tecnologia, informação e tecnologia da informação e sociedade da informação. Discute os espaços que estes conceitos ocuparam em distintos momentos do desenvolvimento humano, como na oralidade, escrita, imprensa e era eletrônica. Finalmente, aborda os impactos que o acelerado desenvolvimento e uso das novas tecnologias da informação estão provocando na sociedade contemporânea
\end{abstract}

\section{Palavras-chave}

Tecnologia da informação; Sociedade da informação; Transmissão do conhecimento.

\section{INTRODUÇÃO: AS DIFERENTES} FASES DA TRANSMISSÃO DE INFORMAÇÕES NA SOCIEDADE

Descrever cronologicamente as diferentes fases da comunicação da informação faz-nos reportar inicialmente à tradição oral, na qual a comunicação baseava-se nas lembranças das pessoas, em especial, em sua memória auditiva. Reporta-nos também à escrita, quando se tornou possível registrar o conhecimento de fatos ocorridos; à imprensa, que agilizou a transmissão da comunicação, fazendo com que mais leitores tivessem acesso ao conhecimento; e finalmente à era eletrônica, que potencializou o armazenamento e a disseminação da informação.

As sociedades, mesmo as mais primitivas, sempre utilizaram alguma forma de transmissão da informação. Num primeiro momento, esta se dava em encontros presenciais nos quais o interlocutor passa- 
va para o receptor a informação que detinha, seja acerca de si mesmo ou de algum assunto relacionado à comunidade como um todo, caracterizando as sociedades orais. O paradigma presente era a experiência: conhecia-se e registrava-se na memória o mundo em que se vivia e as experiências que se vivenciava. Lévy (1993) caracteriza o tempo da oralidade primária como aquele no qual não existe forma de registrar o conhecimento. A oralidade primária utiliza como tecnologia a fala, que tem como função básica a gestão da memória social que se apóia nas lembranças de indivíduos. Nesse caso, a fala é o que liga nossa mente a outras mentes, possibilitando a transmissão do pensamento. Se hoje em dia a palavra tem o poder de criar novas realidades sociais, pode-se imaginar sua influência nas sociedades orais, onde não havia nenhum outro meio de comunicação. Nessas culturas, não existia nenhum modo registrado de armazenar as representações para futura reutilização. A transmissão do conhecimento exigia a idéia contínua de recomeço e de renovação que ocorre de geração para geração. Conclui-se que a história se fazia, na época, por meio da capacidade de memorização dos membros do grupo social e suas preferências. Há, portanto, o registro "incerto" - baseado em interpretações individuais - da realidade filtrada pelo sujeito da ação. A mediação deste é de fundamental importância para a continuidade histórica do conhecimento.

Num segundo momento, a transmissão foi agilizada pela invenção da escrita, tendo o alfabeto como ferramenta fundamental. Com a escrita, o conhecimento de fatos presenciados ou relatos feitos por pessoas que viveram em outras épocas passou a ser possível (DIAS, 1999). Com ela, o discurso pode ser separado da situação particular em que foi produzido, não mais precisando da presença do sujeito social para a reprodução de experiência particular. O seu registro escrito expressa por si mesmo e sofre interferência de quem o "consulta". O tempo e o espaço tornam-se noções diferenciadas das existentes no tempo da oralidade. Há autonomia do texto, em relação à tradição oral. O tempo não é mais o tempo da circularidade, mas o da linearidade, linearidade que desencadeia a história. Qualquer discurso pode ser apreendido, analisado e interpretado fora de seu contexto de produção. A escrita nos faz leitores e a realidade nos é colocada com um filtro mais fino do que ocorria no tempo da oralidade.

Em seguida, assistimos à invenção da imprensa, por Johann Gutenberg na Mongúcia em cerca de 1450, o que facilita a reprodução das informações e permite acesso ao conhecimento para um número cada vez maior de pessoas. Os encontros presenciais tornaram-se a partir daí menos freqüentes e necessários. A imprensa foi definida como "o mecanismo de juntar tipos móveis de metal, cada um possuindo na extremidade superior um caractere alfabético em relevo, que, ao ser entintado e pressionado sobre o material adequado, deixa uma marca ou impressão". Com a invenção de Gutenberg passamos do manuscrito ao papel impresso'.

A utilização do papel permitiu um aumento considerável na produção e reprodução de livros e documentos, influenciando assim a maneira de pensar e agir da humanidade. Surge a categoria dos editores e a dos leitores, quando a leitura e a interpretação adquirem um caráter mais individualizado. As obras começam a incluir representações gráficas mais precisas como tabelas e desenhos e a incorporar mecanismos de leitura anteriores à tipogra-

\footnotetext{
1 O papel foi introduzido no mundo ocidental em meados do Século XII e difundiu-se na Europa entre os séculos XIII e XV.
} 
fia, com interfaces padronizadas entre os conteúdos do livro de forma não linear. As notas de rodapé, por exemplo, remetiam o leitor a outras obras que tratavam do mesmo assunto. O poder de preservação e disseminação do pensamento registrado cresceu enormemente.

Com o surgimento da era eletrônica, o homem desenvolveu nova noção de tempo e espaço: o primeiro torna-se tempo real e o segundo torna-se cada vez menor entre as pessoas. Surge a assim chamada sociedade da informação, que prioriza a informação e a tecnologia, influenciando estilos de vida, padrões de comportamento (lazer, trabalho, consumo), sistema educacional e mercados de trabalho. O impacto de uma velocidade na vida cotidiana nunca antes experimentada pela sociedade ao longo da história é observada na transmissão da informação. As novas tecnologias informacionais, associadas às telecomunicações, desempenham papel fundamental nesse processo. Essa ênfase causa mudanças na construção da estrutura social e na concepção do conhecimento. $\mathrm{O}$ ambiente em que vivemos torna-se permanentemente mutável, exigindo uma atualização e um alto grau de complexidade por parte dos sujeitos sociais e das organizações. As novas tecnologias da informação, visto que potencializam o processo de difusão, disseminação e transferência de informações, tornam-se ferramentas fundamentais nesse processo.

Os períodos da oralidade, escrita, imprensa e era eletrônica apresentam tecnologias distintas na transmissão da informação. O impacto destas formas de comunicação na geração do conhecimento também é distinto. Antes, entretanto, de abordarmos os impactos dessas tecnologias na sociedade contemporânea - foco de nosso trabalho - faz-se necessário a conceituação dos termos tecnologia, informação, tecnologias da informação e sociedade da informação.

\section{CONCEITUAÇÃO DE TECNOLOGIA, INFORMAÇÃO, TECNOLOGIAS DA INFORMAC̃ÃO E SOCIEDADE DA INFORMAÇÃOO}

Uma síntese do caminho percorrido por diferentes autores na tentativa de definição dos termos tecnologia e informação nos ajudará no desenvolvimento do nosso ponto de vista. Para definirmos o termo tecnologia, recorremos à ilustração de Joseph Armand Bombardier (apud PACEY 1983), que testava veículos para trafegar na neve desde 1920. A partir de uma máquina inventada em 1936, com capacidade para carregar até sete passageiros, ele inventa, em 1959, os snowmobiles - uma espécie de trenó motorizado. Esta máquina revoluciona o estilo de vida de nações como Canadá e Estados Unidos. Em um primeiro momento, ela tinha um emprego restrito ao turismo, como meio de transporte e entretenimento em estações de inverno ou veículo para novas modalidades esportivas. Em função de seu sucesso e praticidade, os snowmobiles foram popularizados em países que apresentavam condições climáticas semelhantes às do $\mathrm{Ca}$ nadá e norte dos EUA, como Suécia e Groelândia. Entretanto, os snowmobiles deixaram de ser simples equipamentos turísticos ou esportivos para servir como equipamentos dos quais diversas comunidades dependiam para sua subsistência. Pacey (1983, p.4, tradução dos autores) comenta que

o exemplo do uso dado aos snowmobiles em diferentes culturas serve para ilustrar um ponto comum nas discussões sobre tecnologia. A tecnologia, (...) é cultural, moral e politicamente neutra. Ou seja, produz instru- 
mentos independentemente do sistema de valores de uma localidade e pode ser usada, mesmo imparcialmente, para diferentes tipos de estilo de vida. Assim sendo, tecnologia é algo amoral, que pode ser usado para o bem ou mal. Conquanto a destruição nuclear ou a poluição sejam problemas reais, não estão associados à essência da tecnologia, mas ao uso que é dado à mesma por empresas, governos etc.

Algo importante a ser observado nesse caso é o processo que uma nova tecnologia deflagra na demanda e desenvolvimento de novas habilidades. Para os esquimós que se beneficiaram com o advento dos snowmobiles, surgiu também uma nova realidade: a da necessidade de reserva de combustível e manutenção dos equipamentos, elementos novos na sua cultura e que não eram exigidos quando se utilizavam apenas cachorros como força motriz no seu transporte.

Dentro deste exemplo pode-se apreciar uma corrente de pensamento na qual a tecnologia, na sua essência, é neutra. Dias (1999, p.274) propõe que "a tecnologia em si mesma não é digna de condenação ou exaltação. O uso que se faz dela é que pode ser vil ou nobre". A respeito dessa dualidade, cabe aqui também um outro exemplo: o desenvolvimento da fissão nuclear do urânio que, inicialmente, teve como objetivo a produção de luz e calor mas que, posteriormente, foi utilizada para a construção da bomba atômica, cujo poder de destruição tornou-se mais conhecido por meio da destruição em massa de parte da humanidade.

Então, cabe a pergunta: a tecnologia é realmente neutra? Considerando-se a construção da máquina em seus processos básicos, a resposta será afirmativa. Entretanto, se olhamos de forma mais ampla as atividades ao redor da máquina, que incluem seu uso prático, o status de sua utilização, as habilidades desenvolvidas pelos proprietários, a resposta seria negativa, pois a tecnologia influencia e altera o cotidiano das pessoas - o exemplo dos esquimós é ilustrativo desse fato -e, ao mesmo tempo, os novos desenvolvimentos tecnológicos estão sempre associados e ajustados às culturas nos quais foram gerados ou absorvidos. Existe sempre intenção na ação humana e é esta que muda o valor atribuído à tecnologia. Ou seja, de acordo com essa segunda corrente de pensamento, a tecnologia não é algo neutro.

Os exemplos enfatizados aqui - os snowmobiles e a fissão nuclear - servem de pretexto para situarmos a definição do termo tecnologia dentro da confusa profusão terminológica em que o termo está imerso. Não é rara a visualização do termo tecnologia como sinônimo de inovação. Outrossim, é comum a utilização do termo para designar "ferramentas" utilizadas nos processos de trabalho humano. Cabe, portanto, a recuperação do correto uso da palavra, considerando-se as diferenças entre seus diversos níveis de significância.

A definição do termo tecnologia é complexa e encontra dificuldades de uniformização, por ter um escopo variável entre os diversos autores. Trazer todos os conceitos para o estudo da simples definição de tecnologia parece desnecessário. Entretanto, o que se pode estabelecer de forma clara é que a tecnologia e, consequentemente, a prática tecnológica englobam elementos organizacionais, técnicos e éticos. Para muitas pessoas, o aspecto organizacional seria o mais importante. É representado pelos diversos segmentos da administração e políticas públicas. Refere-se às atividades dos designers, engenheiros, técnicos, 


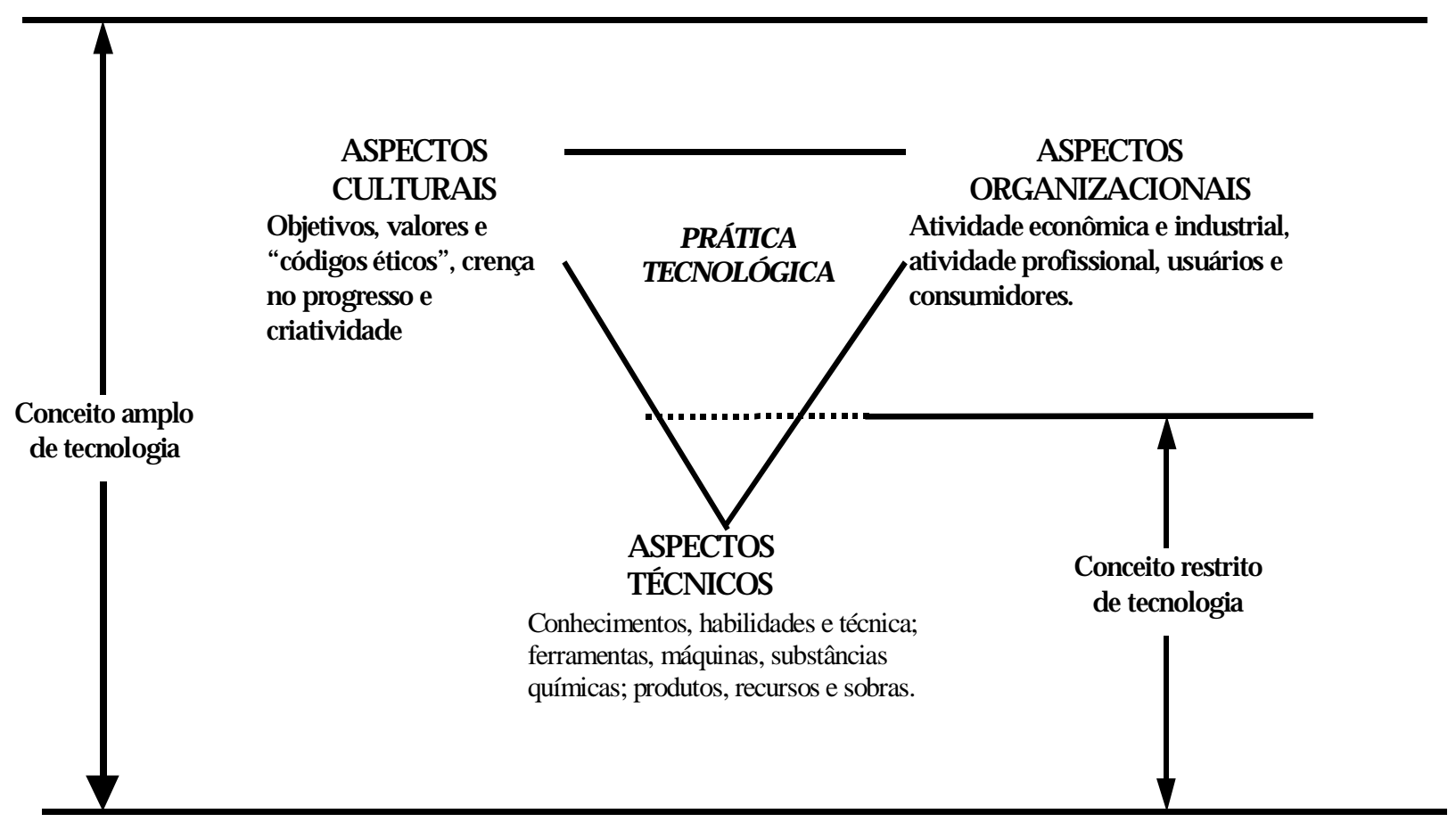

FIGURA.1 Definições diagramáticas de "tecnologia" e "práticas da tecnologia" Fonte: PACEY, Arnold. The culture of technology, 1983, p.6.

operários e também dos usuários ou consumidores daquilo que é produzido. Para outros indivíduos, entretanto, a tecnologia associa-se aos seus aspectos técnicos, pois é realizada com máquinas, técnicas e conhecimentos. É a atividade essencial de fazer as coisas funcionarem. Além disso, há aspectos éticos que influenciam a criatividade de inventores e designers. Seus valores, juntamente com as crenças e maneiras de pensar das comunidades científicas, podem ser indicados como a faceta ideológica ou cultural da prática tecnológica.

A FIG. 1 (acima) ilustra esse conceito e serve para mostrar seu uso tanto em sentido restrito como também geral. Quando a tecnologia é identificada de forma restrita, valores culturais e organizacionais são desconsiderados. Nesse caso, a tecnologia pode ser simplificada em uma palavra: técnica. Seu conceito mais amplo, entretanto, não pode ser entendido enquanto termo livre de valores ou politicamente neutro. Para Galbraith (1972), a tecnologia seria definida como aplicação sistemática da ciência ou de outro tipo organizado de conhecimento para realização de tarefas. Essa definição soa um pouco rasa, mas se nos detivermos mais cuidadosamente na sua análise, podemos verificar que o autor define a tecnologia enquanto atividade que envolve organizações complexas e um claro sistema de valores.

Mas Pacey $(1983$, p.6) defende que o conceito de Galbraith exclui algumas entidades vivas, enquanto salienta pessoas e máquinas. Segundo ele, a tecnologia pode ser entendida como "a aplicação de conhecimento científico ou outro tipo de conhecimento organizado para realização de tarefas práticas através de sistemas ordenados que envolvem pessoas e organizações, coi- 
sas vivas e máquinas". Portanto, neste caso, podemos entender tecnologia enquanto processo de transformação de matérias primas (humana, simbólica ou material) em produtos, vendáveis ou não. Neste enfoque de tecnologia, as máquinas e equipamentos (aspectos técnicos da FIG. 1) são apenas instrumentos, e não a tecnologia em sua totalidade

Definir o termo informação é tarefa tão difícil quanto definir tecnologia. Buckland (1991) ressalta que "informação" guarda ambigüidades e, de fato, é utilizado de diversas maneiras. Ressalte-se também que a definição de informação está de alguma forma relacionada ao conceito de "dado". O que significa "dado" e "informação" e quais seriam as diferenças entre os dois conceitos? Wiggins (1990, p.185) arrisca:

"As respostas" a esta questão variam, dependendo muito da função desempenhada por cada pessoa. Para o analista de dados, por exemplo, dado é considerado como matéria-prima que compõe a informação. Não tem significado a menos que esteja inserido em um contexto.

Essa definição incluiria textos ou literatura publicada? Poderia significar que um texto também não pode ser considerado informação a menos que esteja inserido num contexto. Por outro lado, não é comum referir-se ao texto como dado, embora seja possível referir-se à informação contida num manual de engenharia como um dado útil. Tudo semanticamente um tanto confuso.

Mcgarry (1999, p.2) refere-se ao Information Science Abstracts - publicação que resume inúmeros artigos de periódicos e relatórios de pesquisa no campo da ciência da informação - para ilustrar essa confusão conceitual:
[...] um exame de relance dos cabeçalhos de assuntos ali empregados dará idéia dos vários usos e contextos do termo informação'. Uma pequena amostra mostrará o que quero dizer. Os catálogos das universidades adoram utilizar os termos a seguir. Pense no que significam para você: informática, gerência da informação, informatologia, processamento da informação, recuperação da informação, teoria da informação, transferência de informação, uso da informação e vários outros vocábulos similares.

Esse autor busca na etimologia uma pista para a compreensão do termo informação. O termo torna-se popular logo após a invenção da imprensa no Século XV. Sua raiz encontra-se nas palavras latinas formatio e forma, que transmitem a idéia de formar um molde ou moldar algo. Também estava associada ao termo "notícia".

Partindo do significado "dar forma", Davenport (1998) argumenta que a informação traria uma diferenciação na perspectiva ou insight, através do modelamento por parte da pessoa que a recebe. No entendimento do autor, a informação corresponde a dados que permitem uma diferença, e os seus significados são expressos pelo receptor e não pelo emissor. Quem decide se determinada mensagem de fato informa é o receptor e não o emissor. Ele reforça essa idéia ao afirmar que:

Diferentemente do dado, a informação tem o significado - 'a relevância e propósito' - da definição de DRUCKER. Ela não só 'dá forma' ao receptor como ela própria tem uma forma: ela está organizada para alguma finalidade. Dados tornam-se informação 
quando o seu criador Ihes acrescenta significado (DAVENPORT,1998, p.5).

Buckland (1991), por sua vez, destaca que podemos identificar algumas aproximações para o uso do termo informação. Considerando-se que na aproximação não há como estabelecer um conceito único para o termo, algum progresso pode ser feito. Segundo o autor podemos identificar três usos principais para a palavra informação:

1) Informação enquanto processo: quando se recebe alguma informação, aquilo que se sabia de antemão é mudado pela presença da informação atual. Enquanto processo, ela é ato de informar; comunicar o conhecimento ou notícias de algum fato ou ocorrência; a ação de dizer ou fato de estar sendo dito algo;

2) Informação enquanto conhecimento: é a decodificação daquilo que foi percebido na informação como processo. Seria o conhecimento comunicado a respeito de um fato particular, assunto, ou evento;

3) Informação enquanto coisa: é aquilo que pode ser manipulado como objetos, dado ou documentos, que são definidos como 'informação' porque possuem a propriedade de ser informativos, porque possuem a qualidade de comunicar informações.

Para Buckland (1991) uma característica clara da informação enquanto conhecimento é sua intangibilidade, ou seja, não pode ser tocada ou mensurada de nenhuma forma. Conhecimento, opiniões e valores são pessoais, subjetivos e conceituais. Daí a necessidade de um meio físico para sua expressão, como texto, sinal ou comunicação. A informação, enquanto conhecimento, é portanto representada pela informação enquanto coisa.

Neste sentido, Nonaka \& Takeuchi (1997) afirmam que a informação é um meio material necessário para extrair e construir conhecimento. Na perspectiva dos autores, o conhecimento apresenta importância central, sendo a informação um elemento fundamental para seu desenvolvimento. A construção do conhecimento está essencialmente ligada à ação humana. A informação constitui um fluxo de mensagens, enquanto o conhecimento é criado pelo fluxo dessa informação, ancorado nas crenças e compromissos de seus detentores. É importante ressaltar que tanto a informação como o conhecimento só possuem significância em relação ao contexto, sendo específicos ao mesmo tempo e criados de forma dinâmica na interação social entre as pessoas.

Podemos perceber, portanto, uma enorme profusão de conceitos, apresentando distinções terminológicas, mas sem um consenso claro. Wiener (1960, p.25) assevera que

[...] informação é o termo que designa o conteúdo daquilo que permutamos com o mundo exterior ao ajustar-nos a ele, e que faz com que nosso ajustamento seja nele percebido. Viver de fato é viver com informação.

Essa definição para o termo informação leva-nos a refletir que talvez o aspecto mais importante a ser salientado seja a importância da informação enquanto recurso, que está sendo cada vez mais acentuadamente fundamental para a própria existência humana.

Vale ressaltar que quando dizemos que a informação é um recurso não estamos querendo restringir a definição a uma visão econômica. Conquanto os impactos das novas tecnologias da informação deixem claro que a informação desempenha novo papel nas decisões econômicas, quer sejam públicas ou privadas, estamos interessados na importância e na relevância da informação. A informação pode ser vista 
enquanto recurso, pois possui os requisitos para ser considerada como tal, como diz Cronin (1990):

É uma necessidade. Os custos associados à sua coleta, disseminação, armazenamento, análise, descarte são elevados, o que é contrabalançado pelo fato de [...] possuir valor significativo $[\ldots]$.

Mais importante que definir o termo, é salientar que a informação é sempre um recurso básico para a efetivação dos processos de comunicação humana.

De acordo com as definições de tecnologia e de informação expostas acima, podemos nos aproximar de uma definição de tecnologia da informação como sendo a utilização de conhecimentos científicos ou outro tipo de conhecimento organizado para tratar a informação e viabilizar os processos de decisão humana. A busca de informação surge da necessidade, o que nos faz deparar com escolhas. A tecnologia da informação lida com mecanismos através dos quais os indivíduos fazem suas escolhas com um maior ou menor grau de complexidade, o que influencia diretamente o volume de informação recuperado.

Dessa forma, podemos concluir que a oralidade (dramatizações, ritos, músicas, entonação de voz), a escrita (fundamentalmente o alfabeto) e a imprensa constituem tecnologias da informação, pois correspondem à utilização de alguma forma de conhecimento organizado (gerado e disseminado via informação) para estimular e desenvolver o próprio processo de construção da história da humanidade. É importante ressaltar, que nesse processo de construção e evolução as tecnologias da informação não são excludentes, mas complementares.
Abordemos agora a chamada sociedade da informação. Sua definição passa pelo progresso da tecnologia e da comunicação:

A sociedade da informação é
determinada pela integração das
tecnologias de informação (par-
ticularmente microeletrônica) e
de comunicação à vida social,
profissional e privada, junto com
a percepção da informação
como fator estruturante da soci-
edade e insumo básico de pro-
dução (intelectual, cultural e eco-
nômica) (LUCENA, 1998).

De fato, como destaca Kumar (1999), entramos em novo paradigma de acumulação flexível no qual produzimos informação em massa, da mesma maneira que se produz carros em massa. Os teóricos da sociedade de informação asseveram sobre a existência de um novo quadro no qual as mudanças ocorrem no nível mais fundamental da sociedade, ou seja, a substituição de trabalho e capital, as variáveis básicas da sociedade industrial, por informação e conhecimento.

Gostaríamos de ressaltar que, diante do exposto anteriormente, seja na oralidade, na escrita, na imprensa ou na revolução eletrônica, o homem sempre se colocou frente à tarefa de lidar com a informação. Portanto, a sociedade sempre foi "sociedade da informação". O que vemos ocorrer agora é o aumento na velocidade e nos recursos disponíveis para lidar com a mesma, o que ocorre de forma proporcional ao desenvolvimento da idéia de progresso vivido pela humanidade ao longo da história. Gostaríamos de propor a denominação dessa nova etapa de desenvolvimento da sociedade humana não de "sociedade da informação", mas de "sociedade da informação eletrônica". 
3 OS EFEITOS DAS TECNOLOGIAS DA INFORMAÇÃO NA SOCIEDADE: CONTEXTOS, MUDANÇA E IMPACTO

Abordaremos nesta seção os possíveis impactos da evolução das tecnologias da informação na sociedade, que passou a se denominar sociedade da informação. Nosso enfoque será na sociedade contemporânea que está passando de forma mais rápida e instável por criação e expansão de novas e reestruturantes tecnologias informacionais associadas às telecomunicações, sendo que estas levam à reestruturação até mesmo da definição e entendimento do próprio homem.

Lévy (1993) mostra-se cético quando se fala em impacto das tecnologias. Sua argumentação se apóia no fato de que as tecnologias não apresentam vida própria (não são atores autônomos da sociedade), mas são desenvolvidas, utilizadas e descartadas pelo ser humano, que é o ator principal da sociedade da informação eletrônica. Ele é quem centraliza todo o processo interativo da tecnologia da informação, enquanto agente das atividades humanas, que vive, pensa, constitui entidades materiais, naturais e artificiais com idéias e representações.

Trataremos as tecnologias enquanto processo e produto de determinada sociedade e uma cultura, como visto anteriormente. Enquanto produto cultural, há uma intencionalidade no desenvolvimento e prática da mesma. Por isso, considera-se as mudanças que a sociedade e sua estruturação sofrem em função da utilização das novas tecnologias informacionais e seu impacto.

A Internet, junto às telecomunicações, é tida como a responsável pela interligação do mundo, formando o que hoje se denomina "aldeia global". Essa interligação tem pontos positivos e negativos que serão abordados adiante. Mas, queremos voltar nossa atenção para o "abismo tecnológico" apontado pela ONU em relatório recente citado na Folha de São Paulo (FARAH,2000, p.A13). O referido relatório diz que nem $5 \%$ do mundo usa a Internet. Seu uso encontrase concentrado na Alemanha, Reino Unido, Itália, França, Holanda, Espanha, Canadá e EUA que, juntos, somam $89 \%$ dos usuários. Esse quadro é descrito pela ONU como uma "exclusão digital" da maioria dos países. Essa lacuna, dramática entre países do primeiro e terceiro mundos, tornou-se uma ameaça global:

"Quem não pegar o 'expresso
Internet' será cada vez mais
marginalizado. Países em de-
senvolvimento só poderão com-
petir no mercado global caso
participem dessa revolução"
(FOLHA DE SÃO PAULO, 23
jun. 2000).

A solução proposta pela ONU para combater o "abismo tecnológico" é a ampliação de centros comunitários de acesso ao uso da Internet em escolas e bibliotecas, ao lado de incentivos para países pobres como o perdão de parte da dívida externa $(1 \%)$ e associações dos governos com o setor privado. Para os autores do relatório, os avanços tecnológicos trariam benefícios para a população como um todo não só na área cultural ou educacional, mas também a outras áreas essenciais: "a Internet beneficia a exportação, melhora a administração do setor público e leva informações sobre educação e saúde a muitas pessoas". A pergunta que se tem feito é se há um empenho real dos governos para acabarem com o "abismo digital" já instalado entre os poucos países desenvolvidos e o restante do mundo. Vista como uma panacéia que trará soluções para problemas antigos, a Internet pode tornar-se uma ferramenta de mão única na chamada "aldeia 
global".

É importante salientar, portanto, que conquanto a Internet represente um salto e um avanço na formação de uma aldeia global com impactos marcantes na economia, política e relações sociais mundiais, a formação desse espaço de interação mundial ainda é extremamente restrita. De fato, cabe questionar se existe essa tão falada aldeia global. A sociedade da informação eletrônica, ao invés de representar uma tendência mundial, não refletiria apenas um aspecto dos países desenvolvidos? Obviamente, existe a projeção de uma difusão cada vez maior da Internet, mesmo entre os países pobres. Contudo, se observarmos a tecnologia dentro do conceito de que é neutra, essa expansão não se constituiria em elemento de dominação de países desenvolvidos sobre países de terceiro mundo?

A Internet possibilita a circulação e disponibilização de informações governamentais, organizacionais e pessoais com uma infra-estrutura (como, por exemplo, antenas, satélites) desenvolvida para garantir segurança e proteção à privacidade dos dados que nela circulam. Bravo (1999) argumenta sobre a necessidade de regulamentação sobre o compartilhamento ou não de informações sobre o cidadão pelo governo, pelo setor privado ou outras organizações. Ele se refere a uma forma de proteger o cidadão de possíveis abusos que poderia sofrer por parte desses órgãos. Por outro lado, a Internet pode ser associada a um anarquismo, no qual os assuntos circulam na rede ao mesmo tempo, legalmente ou ilegalmente, às vezes, com muita repetição e em quantidade e qualidade variáveis, o que dificulta o controle sobre a mesma. As novas tecnologias da informação ampliam sua discussão, portanto, para a necessidade de reformular outros campos ou disciplinas do conhecimento como, neste caso, o direito. Lucena (1998, p. 37) comenta sobre este aspecto:

A interconexão entre redes nacionais através de redes internacionais engloba, além de hardware, software e trabalho técnico necessário para a instalação, operação e manutenção de uma infra-estrutura global, os aspectos de padronização, legal, comercial e diplomático.

Por outro lado, o próprio cidadão pode ter hoje acesso a informações que não estariam disponíveis em meios públicos, no período anterior à Internet. Por exemplo, pode-se ter acesso a toda a movimentação financeira de uma empresa a partir de um terminal de auto-atendimento, onde também assistimos ao virtual desaparecimento de cheques e dinheiro na maioria das transações monetárias. Operações como esta, que envolvem protocolos e linguagens de exibição, eram impensáveis antes do desenvolvimento das novas tecnologias informacionais.

As novas tecnologias também têm sido utilizadas criminosamente, como é o caso do acesso não autorizado pelos hackings, que agem sobre programas e bancos de dados, cometendo fraudes e disseminando vírus (LUCENA, 1998). Em contrapartida, esses problemas estimulam desenvolvimento de novas tecnologias como a criptografia ${ }^{2}$ que possibilita imprimir um alto nível de segurança na utilização da rede.

A globalização poderia ser vista como uma possibilidade de melhoria das condições de vida de todos, mas o que se vê, cada vez mais, é um processo de exclusão crescente daqueles que não conseguem

${ }^{2}$ Criptografia pode ser definida com "a ciência de misturar dados de maneira que os olhos errados não vejam". (IBICT, CNPQ, 1998, p.33). 
acompanhar o "expresso Internet". Lucena (1998) afirma que a entrada do Brasil na rede global deveria ocorrer de forma a assegurar a preservação e ampliação de sua diversidade cultural, e sua segurança deveria ser tratada como item de interesse nacional nos intercâmbios de toda e qualquer natureza. Tentaremos adiante apontar alguns dos efeitos dessa corrida rumo ao "expresso".

Do ponto de vista das relações de poder, as interações entre os sujeitos tendem a ser mais e mais polarizadas - caracterizando os dominadores e os dominados - pela presença da tecnologia. Há uma preocupação por parte de órgãos nacionais, como o IBICT e o CNPq, do Brasil, evitar a passividade típica dos países do terceiro mundo que não assumem uma posição de agentes efetivos na reorganização dos modos de produção e negócios em tempos de globalização. A aceleração desse processo no Brasil se dá pela incorporação das tecnologias da informação, comunicação e computação, o que significa entrar no mundo virtual assegurado pela Internet e rede menores. Essa inserção exige investimentos tanto humanos quanto financeiros, devendo-se observar que aqueles que detiverem maiores recursos nessa área, terão maior chance de ditar as regras de construção, utilização, disponibilização e acesso às informações. Os países menos favorecidos surgem nesse cenário como consumidores passivos das informações que são disponibilizadas na rede. Devemos atentar-nos para o fato de que nem todas as informações relevantes estão circulando livremente ou com acesso ilimitado na Internet. Há uma censura operando em assuntos tratados como interesses particulares, mesmo que os mesmos afetem parcela significativa da humanidade. Como exemplo de monopólio e poder nessa área, temos empresas multinacionais conhecidas como a IBM (computadores), AT\&T (telecomunicações), Xerox e Olivetti (equipamentos de escritório), Philips e Siemens (eletrônica).

Podemos mais uma vez argumentar que somente poucos se encontram envolvidos diretamente na produção, disseminação e utilização destas tecnologias (cerca de $5 \%$ da população mundial, segundo relatório da ONU). Alguns as recebem como algo externo (o que é exacerbado pela rapidez com que ocorre sua expansão), que chega e muda tanto a rotina pessoal quanto a profissional. Quem não se adapta corre o risco ser excluído das relações interpessoais ou de trabalho e quem se atualiza, constantemente, tem mais chances de compor os recursos humanos da era da informação:

Os recursos humanos qualifica-
dos serão de importância funda-
mental para a era da informação:
cientistas, engenheiros, educa-
dores e técnicos; uma força de
trabalho treinada para o uso des-
tas tecnologias e sistemas capaz
de produzir com qualidade e
competitividade dentro de ambi-
entes baseados em conheci-
mento e uma população prepa-
rada para, em escala generali-
zada, utilizar sistemas e serviços
associados a redes de comuni-
cação e informação, bem como
educada para produzir e consu-
mir informação e conhecimento
competentemente (LUCENA,
1998, p.37-38).

Por ocasião do surgimento da escrita, algumas línguas e, mesmo sociedades, desapareceram por não terem se adaptado, em tempo hábil, às novas tecnologias. Com a globalização, vimos surgir a hegemonia da língua inglesa nos contatos sejam financeiros, políticos ou culturais. $\mathrm{O}$ domínio desse idioma começa a ser determinante para um trânsito confortável em um mercado profissional cada vez mais competitivo. 
O mesmo relatório da ONU que denuncia que o controle da informação está nas mãos de uma pequena minoria, atenta para a necessidade de tradução de sites do inglês para outras línguas, como o árabe, chinês e persa a fim de contribuir na socialização da Internet (FARAH, 2000, p. A13). Essa hegemonia está estritamente ligada ao capitalismo dos países do primeiro mundo. Hoje, assistimos a reações contra a hegemonia do inglês como, por exemplo, a exigência dos franceses de que os cardápios da rede Mcdonald's venham escritos em francês. Mas, estas reações são poucas e predominam os valores norteamericanos ditando hábitos, modas e cultura para grande parte da população mundial. Por isso, uma reflexão sobre a era da informação e, em última análise, a construção de um mundo informacional mais democrático, requer necessariamente uma postura crítica sobre essa realidade em que todos vivemos.

Com relação à construção da inteligência, fala-se na inteligência coletiva possibilitada pelo ciberespaço (dispositivo de comunicação interativo e comunitário). Os hipertextos (escrita não seqüencial que permite ao leitor fazer uma leitura individualizada) são possibilidades da construção coletiva e eliminação da autoria individual, como afirma Lévy (1993).

É verdade que há um autor para a estrutura, mas há o fato de que a manipulação do hipertexto é limitada pela estrutura sobre a qual seu autor o constrói. Há um caminho pré-determinado a ser seguido. A não ser que ele nos dê uma estrutura aberta, com a possibilidade de criar links, não podemos traçar nosso próprio caminho. Lévy afirma que o ciberespaço é apenas um ambiente para o desenvolvimento da inteligência coletiva, o que não garante o seu desenvolvimento.
O desenvolvimento do conhecimento e a criação da inteligência coletiva não se dão somente do ponto de vista quantitativo, mas também qualitativo. Não mais se atingem platéias uniformes via mensagens padronizadas. A estrutura hipertextual do ciberespaço permite ao leitor expandir seu conhecimento além das notas de rodapé e sumários. Tornou-se possível transitar no texto conforme se deseje. Apesar de visualizarmos claramente, no hipertexto, um caminho a ser seguido, com uma estruturação finita dentro da proposta do seu autor, o leitor poder transitar aí livremente, sem modificar essa estrutura.

A formação da inteligência coletiva permite que a informação seja processada, selecionada e recuperada por qualquer um que tenha acesso à rede que se formou. Se esse conhecimento é modificável em uma velocidade nunca antes vivida na história da informação, será que isto não seria uma barreira para a sedimentação do conhecimento produzido na rede? Não nos faltaria uma consistência de conteúdo ou conhecimento para utilização posterior, que fosse útil na construção da história, na melhoria das condições de vida da sociedade como um todo? Será que as pessoas disporiam de meios para lidar com essa falta de estabilidade dentro da virtualidade do ciberespaço? Suscitamos essas questões por causa da volatilidade a que estão sujeitos os produtos da inteligência coletiva. Não temos a pretensão de responder a estas questões, mas consideramos que essa reflexão seja importante, para que se previna o que Breen (1997) aponta como o esvaziamento do conhecimento racional e histórico.

Associadas ao desenvolvimento da tecnologia e da criação da inteligência coletiva, surgem formas de comportamento pouco saudáveis, como o isolamento e a sobre- 
carga cognitivos (diminuição da interação presencial e, com ela, perda de referências reais); a dependência (vício na navegação ou jogos em mundos virtuais); a dominação (reforço dos centros de decisão e de controle, domínio quase monopolista de algumas potências econômicas sobre funções importantes da rede etc.); a exploração (em alguns casos de teletrabalho vigiado ou de deslocalização de atividades no terceiro mundo) e, mesmo, as "bobagens" ou "perversões" coletivas (LUCENA, 1998).

As tecnologias informacionais podem aumentar a autonomia dos indivíduos e multiplicar suas capacidades cognitivas, como por exemplo, a extensão da memória em longo prazo e a leitura individualizada de hipertextos. Essa mudança apresenta um impacto na forma como os sujeitos se posicionam frente ao mundo, podendo leválos a uma busca, uma reformulação deste a partir do mundo virtual, o que é bastante plausível dentro de um mundo caracterizado por uma grande ausência de estabilidade e um foco muito grande na virtualidade da Internet. Como a inteligência coletiva irá ajudar-nos a lidar com o mundo "real" não é revelado nas discussões dos autores que tratam do assunto. Não se sabe mesmo se há uma preocupação nesse sentido, mas há que se considerar o potencial de impactos negativos na construção de uma inteligência coletiva.

O computador permite uma grande velocidade na comunicação, uma simulação (através da demonstração visual) e a não linearidade do texto (possível pelos links de conexões do hipertexto). A transformação não se dá apenas na transmissão da mensagem, mas também na recepção e interpretação que cada um dará à mesma, através da mobilidade das relações de sentido. Transferindo-nos para a realidade das nossas relações interpessoais e para a realidade das relações homem/máquina, podemos constatar que as mensagens através do meio eletrônico estão cada vez mais imediatas e que o hipertexto permite-nos ultrapassar o formato uniforme de uma página. Os textos informatizados variam muito e se adaptam de acordo com o leitor. As imagens simuladas funcionam como uma extensão da imaginação.

A informática representa muito mais que uma revolução nas formas e métodos de geração, armazenamento, processamento e transmissão da informação. A possibilidade de se explorar o texto de maneira interativa introduziu o conhecimento por simulação. O hipertexto também desterritorializa o texto, tornando-o sem fronteiras.

Parece que a inteligência coletiva descrita por Lévy (1993) se limita à interação no ciberespaço de construção de textos, hipertextos coletivos, de relações virtuais, não sendo extrapolada para a realidade. Entendemos essa extrapolação enquanto uma construção do mundo real de forma coletiva e interativa. Entretanto, no mundo real, muitas vezes alguns poucos tomam as decisões e a maioria apenas sofre os efeitos dessas decisões. Portanto, a inteligência coletiva não garante uma melhoria nas relações entre as pessoas ou uma reformulação da sociedade no sentido do bem comum.

As tecnologias da informação estão descortinando novas oportunidades de pesquisa. Através dos computadores, diz Meadws (1999), pode-se decidir quais temas de pesquisa atraem maior interesse. Para esse autor, a maioria das grandes instituições de pesquisa adotam políticas de comunicação em rede. Os pesquisadores, para se encaixarem neste perfil, passam a depender de habilidades em informática. Contudo, esse conhecimento deve ser equilibrado para não haver um desvio do foco de pesquisa em direção às funções técni- 
cas. Outro risco que se corre é que os problemas a serem pesquisados se concentrem em torno daqueles que interessam somente aos países desenvolvidos, que são aqueles que detêm as tecnologias mais avançadas e maior capital financeiro ou intelectual.

Uma modificação no perfil dos pesquisadores também pode ocorrer na medida em que, não havendo um encontro presencial, se sentem mais livres para questionar. Esta comunicação facilitada no espaço virtual os permitiria agirem em pé de igualdade. O semi-anomimato na comunicação mediada pelo computador pode permitir uma maior igualdade, o que parece facilitar as interações entre os cientistas e possibilitar o desenvolvimento mais crítico da pesquisa (LUCENA, 1998).

Volta aqui a questão do acesso à informação, onde só quem o tiver poderá fazer parte do diálogo e ser ouvido. É claro que a discussão virtual também permite a omissão ou o não comprometimento, mas a formação de grupos virtuais de discussão científica é uma importante contribuição para o desenvolvimento da pesquisa, pois pode estimular o trabalho em grupo e a formação de novas equipes de pesquisa.

Um outro lado da tecnologia informacional na área de pesquisa referese ao aspecto ético. Hoje, o Projeto Genoma é bastante questionado sobre até que ponto o desenvolvimento da manipulação genética visa uma melhoria da vida humana ou mais uma forma de acentuar a polarização econômico-social mundial?

Se nas sociedades orais, a economia restringia-se à subsistência, nas sociedades posteriores já havia uma preocupação com o controle da produção, o que viria a possibilitar as trocas de valores e a instauração de mercados. Já no presente perío- do da globalização, assistimos um deslocamento econômico da indústria para o setor de serviços, da força física para o conhecimento. Aeconomia circula em torno de capitais virtuais, envolvendo a maioria das transações comerciais em todo o mundo. Os acontecimentos políticos, econômicos e culturais não são mais eventos isolados. Fatos acontecidos em um país, como a troca de determinada moeda ou aprovação de leis, passam a afetar a cotação de ações e índices em bolsas de valores em todo o mundo.

Informacional, global, interdependente, politizada, regionalizada, variável, assimétrica, seletiva, excludente, e focada na competitividade são algumas das principais características da economia na sociedade contemporânea. Essas características se inter-relacionam de forma dinâmica. A informação, rapidamente incorporada aos processos de trabalho pela rede global, permite às empresas operar em tempo real, transcendendo fronteiras políticas e geográficas. As empresas necessitam, por isso, se adaptar às finalidades e aos mercados específicos na nova ordem de produção e comercialização. Deve-se buscar uma flexibilização interna, refletida na capacidade de admitir e demitir conforme flutuações de mercado e na horizontalização da hierarquia organizacional; e uma flexibilização externa, refletida na capacidade de adequar os produtos às demandas do mercado e seus segmentos. A acentuação da concorrência nos mercados internacionais também faz surgir a necessidade de um controle mais acurado das transações.

A característica da regionalização, vista acima, encontra-se estreitamente relacionada às características de assimetria e exclusão. Assistimos, na história recente, à formação de três regiões de grande crescimento tecnológico: América do Norte, União Européia e região do Pacífico Asiático. Por outro lado, o Terceiro Mundo, que contém a 
maior parte da população mundial, não apresenta um crescimento significativo que faça frente a esse quadro. A característica da variabilidade da economia associa-se diretamente à evolução das tecnologias informacionais que possibilitam mudanças econômicas com impactos em regiões distantes geograficamente, como por exemplo, o impacto da crise dos chamados tigres asiáticos nas bolsas de todo o mundo:

Os principais mercados de ações do mundo, eletronicamente ligados, fazem ajustes instantâneos nos preços das ações, em resposta a informações transmitidas minuto a minuto por telas de computador. A compra e venda de ações durante as 24 horas do dia tornam-se, pela primeira vez, uma possibilidade e, cada vez mais, a prática (KUMAR, 1997, p.28).

A economia capitalista apresenta, como objetivo último, o lucro e a acumulação de capital, com repercussões diretas sobre o mundo globalizado e interligado, com nítidos efeitos sociais para uma grande parcela de países, que já começam a ser desconsiderados. Boa parte dos países do continente africano, apesar de detentores de importantes matérias-primas, como o garimpo de diamantes em Angola, ainda têm populações vivendo em condições subhumanas. A maior parcela do lucro da economia mundial concentra-se nas mãos das grandes potências, como os EUA, que se posicionam frente ao resto do mundo com um discurso ambíguo de investimento e incentivo para economias locais. Alguns autores, como Kurz (1996), prevê a chegada de um momento em que os povos excluídos da rede mundial de informação sequer constarão das estatísticas econômicas mundiais.

$\mathrm{Na}$ área educacional, o ensino presencial foi reestruturado com a introdu- ção das novas tecnologias informacionais e suas associações com a comunicação e multimídia, que possibilitaram, entre outras coisas, do desenvolvimento da educação à distância. O ensino tornou-se mais interativo e mais atraente para o aluno, cujo processo de aprendizagem passou a ser tratado de forma mais individualizada. Entre os novos recursos, há o acesso às bibliotecas virtuais e o acesso on line, que atendem desde programas de treinamento de empresas a programas que buscam a solução de problemas específicos. Entretanto, há um outro lado em que o acesso facilitado a essas novidades torna-se problemático, principalmente entre os adolescentes, que passam a utilizar menos a elaboração intelectual, valendo-se de informações já processadas. Na produção de textos originais, por exemplo, a prática disseminada dos comandos "recortar/colar" dos processadores de texto dificulta a elaboração criativa e a visão geral do que se escreve.

A questão do poder perpassa a questão da educação, especialmente nos países em desenvolvimento, com sua típica carência de recursos para investir em implantação e atualização das tecnologias informacionais. Essa carência deságua em desigualdades em que esses países podem cair, com implicações técnicas, sociais, políticas e econômicas que podem ser cumulativas e irreversíveis. Na sociedade da informação eletrônica, investimentos cada vez maiores em educação fazem-se necessários pois, como afirma Lucena (1998, p.37-38):

mais do que em qualquer outra era da história da humanidade, recursos humanos qualificados serão de fundamental importância para a era da informação: cientistas, engenheiros, educadores e técnicos em todas as áreas associadas às tecnologias 
da informação, especialmente em sistemas de informação, de comunicação e computação, mas também em administração e aplicação de informação e conhecimento;

- uma força de trabalho treinada para o uso destas tecnologias e sistemas capaz de produzir com qualidade e competitividade dentro de ambientes baseados em conhecimentos;

- uma população preparada para, em escala generalizada, utilizar sistemas e serviços associados a redes de comunicação e informação, bem como educada para produzir e consumir informação e conhecimento competentemente.

Segundo relatório da ONU publicado na Folha de São Paulo em junho de 2000, desde 1995, o Brasil apresenta a maioria de suas universidades e centros de pesquisa interconectados, oferecendo serviços para apenas 150 mil usuários o que, segundo nossa perspectiva, não representa condição suficiente para se atingir a qualidade dos recursos humanos que a sociedade da informação eletrônica exige.

Hoje, assistimos o delineamento de um novo perfil profissional que deve passar por um processo de contínua atualização, onde as novas tecnologias informacionais tornam-se imprescindíveis. A flexibilidade torna-se condição de sobrevivência, mas a exigência de uma constante mudança do conhecimento do profissional gera uma sobrecarga excessiva para o trabalhador, cujas estruturas psíquica, cognitiva e física não se alteram no mesmo ritmo das novas tecnologias informacionais.

As novas tecnologias informacionais alimentam, em alguns profissionais como arquitetos, desenhistas industriais e trabaIhadores de escritório, uma "dinâmica de desqualificação", ao mesmo tempo em que criam e expandem novos tipos de trabalho no setor do conhecimento. Não há, entre os autores que estudam o assunto, consenso se essas tecnologias reduzem ou aumentam postos de trabalho. Mas,

na medida em que o taylorismo continua a ser o princípio dominante, a tecnologia da informação possui maior potencial de proletarizar do que de profissionalizar o trabalhador (KUMAR, 1997, p.37).

Segundo o mesmo autor, o crescimento do número de empregos tem ocorrido não no setor do conhecimento, mas no setor de serviços, ou seja, nos níveis mais baixos da economia, no qual o grau de habilidades e conhecimento não é alto. Em outras palavras, essa "desqualificação" escondese sob novas formas de utilização da força de trabalho. Acrescenta-se aí impactos psicológicos como depressão e neurose de trabalho (síndrome do trabalho vazio em bancários, neuroses das telefonistas etc.).

As empresas modernas sofreram um processo de horizontalização no qual o controle dos trabalhadores considera um novo parâmetro que encontra-se embutido nos próprios equipamentos e nas formas coletivas que asseguram a participação regulada. Surgem também grupos de trabalho semi-autônomos, aparentemente segundo um modelo organizacional descentralizado, em que é possível planejar, decidir e organizar o próprio trabalho nos diferentes níveis organizacionais. Como são semi-autônomos, há diminuição da diferença entre trabalho prescrito e real (SALERNO, 1994). Apesar disso, observa-se a emergência de novas fontes de sofrimento no trabalho. $O$ sofrimento psíquico aparece quando todas as margens de liberdade na transformação, na gestão e no aperfeiçoamento da organização do seu trabalho já foram eliminadas.

Inf.Inf., Londrina, v. 7, n. 2, p. 75-94, jul./dez. 2002 
O medo ou temor surgem como uma reação à possibilidade de perda do emprego decorrente da substituição do homem pela máquina ou da possibilidade de cometer erros (DEJOURS, 1994). Nas linhas de produção, o trabalho do homem pode ser substituído por robôs ou máquinas de controle numérico para assegurar uma estratégia concorrencial forte, que busque a qualidade e a diferenciação dos produtos e serviços no mercado.

A utilização de tecnologias informacionais permite a integração e a aproximação das relações entre as empresas, seja pela interligação de tarefas e pessoas, seja pela articulação interempresarial com o objetivo de reunir esforços cooperativos de desenvolvimento tecnológico (joint ventures). Surge o discurso de valorização do potencial humano, tornando-se o ser humano o principal valor ativo no qual deve-se investir, discurso que acreditamos ser muito mais intelectualizado do que praticado.

A conectividade, possibilitada pela Internet, ao mesmo tempo em que atinge o processo de trabalho do sujeito, interfere em sua vida privada. Uma pesquisa realizada no vale do Silício por Richard, cita o fato de filhos adolescentes atuarem como consultores para seus pais na compreensão e aprendizagem de novos software. Cita também o caso de casais trabalharem cem horas por semana, praticamente sem se desconectar, chegando a levar laptops para a cama (FARAH, 2000,p.A13). Esse processo é nomeado pela psicopatologia do trabalho como "contaminação do tempo fora do trabalho" e tem sido objeto de muitos estudos na área da psicologia do trabalho sobre os chamados workaholics.

As novas tecnologias afetam também as formas de entretenimento e socialização. Hoje, há várias formas de entretenimento virtual possibilitadas pela interação das tecnologias informacionais (Internet, CDRom etc.). Pode-se formar, por exemplo, grupos de amigos on line com hora marcada para se encontrarem virtualmente em determinado local (os chamados chats). A distância parece oferecer aos "amigos virtuais" uma segurança que um encontro pessoal não permitiria. São comuns relatos em que a relação virtual torna-se impossível quando tornada real. Assistimos também à emergência de temas existenciais como o tédio, o vazio e a solidão na sociedade pósmoderna, que podem estar relacionados com a convivência na realidade virtual, com a "cultura do simulacro" (TAYLOR, 1994). Lasch (1979, p. 339) argumenta que "seria a um desprendimento emocional que os indivíduos cada vez mais aspirariam, em razão dos riscos de instabilidade que as relações pessoais conhecem em nossos dias. Ter relações interindividuais sem ligação profunda, não se sentir vulnerável, desenvolver sua independência afetiva, viver sozinho, tal seria o perfil do narciso". Na mesma linha de pensamento, Lipovetsky (1983, p.73) afirma que quanto mais se desenvolve a possibilidade de encontros virtuais entre as pessoas, via tecnologias informacionais, mais solitárias elas se sentem: "Por toda a parte encontramos a solidão, o vazio, a dificuldade de sentir, de ser transportado para fora se si". O autor define a "era" pós-moderna como a "era do vazio", na qual as pessoas se envolvem em encontros e discursos virtuais, construídos sobre uma realidade esvaziada de sentido. Ele define a sociedade como uma sociedade do espetáculo, em que os EUA representam seu pivô de construção.

A facilidade de se obter entretenimento em grande quantidade e no horário em que se deseja não parece ser uma solução para que o homem sinta-se integrado socialmente. Impera a necessidade de se buscar sentido naquilo a que nos dedicamos. Ajudar o ser humano a encontrar-se não parece tarefa fácil, especialmente num mundo orienta- 
do pela acumulação virtual do capital, onde o ser humano é catalogado apenas como um número dentro da rede.

\section{CONCLUSÃO}

Durante a história da humanidade foram utilizadas diversas tecnologias na comunicação e desenvolvimento das sociedades. Entretanto, no último quartel do Século XX, o desenvolvimento da computação e das telecomunicações permitiu um avanço significativo na troca de informações e na geração do conhecimento. A chamada sociedade da informação tem trazido, desde então, impactos significativos no dia a dia das pessoas.

Ressaltamos neste trabalho alguns desses impactos sob um viés essencialmente crítico. Não se trata de neoludismo da nossa parte e certamente não desvalorizamos as tecnologias da informação. Alertamos contra distorções que possam haver na utilização das novas tecnologias. Afinal, os autores estudados relataram várias possibilidades, muitas vezes contraditórias. Mas, antes de finalizar a discussão, não podemos ignorar as perspectivas sombrias da globalização, como o agravamento da exclusão e da marginalização de povos e a perda de identidades e diversidades culturais.

As tecnologias, por si só, não geram desenvolvimento ou possibilitam uma melhoria nas condições de vida para os indivíduos da "aldeia global". É necessária uma interação efetiva entre os setores privado, governamental e ONGs para a formulação de políticas de desenvolvimento que contemplem os aspectos positivos das tecnologias da informação e minimizem os efeitos negativos da aplicação das mesmas. Aí sim poderemos encarar o futuro com otimismo.

\section{REFERÊNCIAS}

BRAVO, Rodolfo Herrera. El Derecho em la sociedad de la Información: nociones generales sobre el Derecho de las Tecnologías de la Información y las Comunicaciones. Disponível em http:// www.ctv.es/USERS/mpq/estrado002.html

BREEN, Marcus. Information does not equal knowledge: theorizing the political economy of virtuality. Journal of computer Mediated Communication, v.3, n.1, Dec.1997. Disponível em http://www.ascusc.org/jcmc.

CASTELLS, M. A. A sociedade em rede. São Paulo: ED. Paz e Terra, 1999, 617p.

DEJUORS, C. Psicodinâmica do trabalho: contribuições da Escola Dejouriana à análise da relação prazer, sofrimento e trabaIho. São Paulo: Ed. Atlas,1994. 145p.

DIAS, Cláudia Augusto. Hipertexto: evolução histórica e efeitos sociais. Ci. Inf. Brasília, v.28, n.3, p. 267-275, set/dez. 1999.

DIRINGER, David. A history of the alphabet. 3 ed. London: Hutchinson, 1968, p.14.

FARAH, PAULO DANIEL. Nem $5 \%$ do mundo usa Internet, diz a ONU. Folha de São Paulo, São Paulo, 23 jun. 2000. Caderno Mundo, p. A 13.

KUMAR, Krishan. Da sociedade pós-industrial à pós-moderna: novas teorias sobre mundo contemporâneo. Trad. Ruy Jungmann. Rio de janeiro: Ed. Jorge Zahar, 1997.

KURZ, Robert. O Colapso da modernização: da derrocada do socialismo de caserna à crise da economia mundial. Tradução de Karen Elsabe Barbosa. São Paulo: Paz 
e Terra, 1996.

LÉVY, Pierre. As tecnologias da inteligências: o futuro do pensamento na era informática. Tradução de Carlos Irineu da Costa. Rio de Janeiro: Ed34, 1993. 203 p. Cibercultura. Trad. de Carlos Irineu da Costa. São Paulo: Ed34, 1999. 264 p. O que é o virtual. Trad. Paulo Neves. São Paulo: Ed 34, 1996.160 p.

LIPOVETSKY, Gilles. A era do vazio. Lisboa: Relógio D’Água, 1983.

LUCENA, Carlos José Pereira, CAMPOS, Ivan Moura, MEIRA, Silvio Lemos (Eds.) Ciência e tecnologia para a construção da sociedade da informação no Brasil. Brasília: CNPq/IBICT, São Paulo: Instituto UNIEMP, 1998.

McGARRY, Kevin. O contexto dinâmico da informação: uma análise introdutória. Trad. Helena Vilar de Lemos. Brasília, DF: Briquet de Lemos/Livros, 1999. 206 p.

MEADOWS, A. J. A comunicação científica. Brasília, Distrito Federal: Ed. Briquet de Lemos/ Livro, 1999.

NONAKA, Ikujiro, TAKEUCHI, Hirotaka. Criação de Conhecimento na Empresa: como as empresas japonesas geram a dinâmica da inovação. Rio de Janeiro: Campus, 1997.

PACEY, Arnold. b. Cambrige, Massachusetts: The MIT Press, 1983.210 p.

SALERNO, Sérgio. Trabalho e organização na empresa industrial integrada e flexível. In: FERRETTI, Celso João, DAGMAR, M. L. Zibas, MADEIRA, Felícia R. \& FRANCO, Maria .Laura P. B. Novas tecnologias trabaIho e educação: um debate multidisciplinar.
Petrópolis, Rio de janeiro: Ed. Vozes, 1994, p.54-76.

VALLE, Benjamim Medeiros. Tecnologia da informação no contexto organizacional. Ciência da Informação/Instituto Brasileiro de informação em ciência e tecnologia, v.25, n.1, 1996.

\section{Gercina Ângela Borém de O. Lima}

Professora da Escola de Ciência da Informação da UFMG. Doutoranda do Programa de Pós-Graduação da Escola de Ciência da Informação da UFMG. E-mail: 
glima@eb.ufm.br Site:www.eb.ufmg.br/glima

\section{Líliam Pacheco Pinto}

Mestranda do Programa de Pós-Graduação da Escola de Ciência da Informação da UFMG.

E-mail: liampacheco@hotmail.com

\section{Marconi Martins de Laia}

Mestrando do Programa de Pós-Graduação da Escola de Ciência da Informação da UFMG.

E-mail: marconi@fjp.gov.br

\section{Title}

Information technology: impacts on society

\begin{abstract}
This article deals with the terminology and concepts of technology, information, information technology and information society. Discusses the role these concepts played in different phases of mankind's development such as in oral society, written society, printed era and electronic age. It is also focused the impact of the new technologies and their applicaton in the contemporary world.
\end{abstract}

\section{Keywords}

Information Technology; Information Society; Knowledge Transfer.

\section{Titulo}

Tecnologia de la información: impactos en la sociedade

\section{Resumen}

Estudia los conceptos de los termos tecnología, información y tecnología de la información y sociedad de la información. Discute los espacios que estos conceptos ocuparon en distintos momentos del desenvolvimiento humano, como en la oralidad, escrita, prensa, y la era electrónica. Finalmente, aborda los impactos que el acelerado desarrollo y uso de las nuevas tecnologías de la información están provocando en la sociedad contemporánea.

\section{Palabras-clave}

Tecnología de la Información; Sociedad de la Información, Transmisión del Conocimiento

Artigo recebido em: 31/10/2001 